\title{
THE FORMULATION OF TASTE AND VALUE IN AMERICAN ACTION-SPY MOVIES: AN ANALYSIS OF THE BOURNE SAGA
}

\author{
Muchammad Sofyan Firmansyah \\ sofyanfirman19@gmail.com
}

\begin{abstract}
The popularity of Hollywood action movies is undisputed, especially the ones related to espionage. The movies such as the 007 series and Mission: Impossible series are best known as successful action-spy movies as they are always considered the top blockbuster movies. However, the start of the release of The Bourne movies in 2002 changed audiences' perspectives toward the depiction of espionage as commonly shown in 007 and Mission: Impossible. Four of The Bourne movies that consist of The Bourne Identity (2002), The Bourne Supremacy (2004), The Bourne Ultimatum (2007), and The Bourne Legacy (2011) are used as the object of this research. Furthermore, the different depictions of espionage in The Bourne movies successfully reached the attention of action-spy audiences. Many audiences from throughout the world expressed their feelings after watching these movies on the movie review site as IMDb.com. The audiences' responses toward the different portrait of espionage that are presented in the movies may depend on the taste of those audiences with regards to the depictions inside the movies that may present certain American values as the narrative of the movies concerns an American named Jason Bourne. There are two goals of this research. The first is to reveal whether there is any relation between audiences' taste and the values depicted in movie whether these movie are products of popular culture or not. The second is to know how these movies mold the American values in their narrative to appeal to the desire of audiences. This research is conducted under the American studies discipline, especially the paradigm of transnational American Studies. Furthermore, some theories are employed as tools to analyze the object in order to achieve the goal of this research. Conducted as qualitative research, books, movies, articles, and videos related to the focus of this research are used as supporting data.
\end{abstract}

Keywords: The Bourne, Audience, Taste, Value

\section{Introduction}

The popularity of Hollywood movies, especially the ones belonging to the action genre, is unbeatable. People tend to love in watching the depiction of action, especially the battles between good and evil. However, making these kinds of movie that is accepted by many people is not easy task to do. The moviemakers must mold certain aspects in society into their movies as one of many important ways to popularize their movies. They will go to such a great lengths of research in order to mold their movies into a reflection of the audiences' beliefs and values for the sake of the success of their movies (Nachbar \& Lause, 1992, p. 7). This proccess must be done because movie as a product of popular culture must carry cultural beliefs as they express complex feelings, values, and ideas 
through symbols and myths (Cawelti, 1976, p. 7).

These action movies have certain formulas that always attract people to watch it. The formula such as "the narrative that tends to show the battle between the good versus the bad (Adi, 2008, p. 68)”, has been repeatedly adapted to some action movies, some of it become box office hits. It is not a secret that some action movies such as Die Hard, Cliff Hanger, Lethal Weapon and Under Siege were also popular because of their adaptation to the action formula.

Nowadays, the action movies with depiction of espionage have become the most popular ones. Some box-office movies such as the 007 franchise, Mission: Impossible franchise, and Jack Ryan franchise present the same depiction of espionage. The repetition of the depiction of espionage in action movies established a success that has created an independent sub-genre, spy, under the action genre. Some small budgeted movies such as Kingsman: The Secret Service (2015) and Hitman: Agent 45 (2015) that adapted the depiction has also been profitable.

However, the depiction of the action formula that is repeated in many action movies makes the audiences want to see something different. Consequently, moviemakers have to observe the latest issues that are happened on the society in order to create a movie that will meet audiences' tastes. Furthermore, moviemakers also must imply certain values of society in the narrative of their movies in order to attract the audiences, as Brockmeier \& Carbaugh (2001) argued "narrative is erected upon a universal value-logic of presumably 'good reasons' that it presumes particular beliefs and actions as a condition for its production (p. 11).”

On 2000s, The Bourne Series that is an adaptation of Robert Ludlum's famous novel is presented differently rather than other action movies at that time. The movie which currently consists of four movies: The Bourne Identity (2002), The Bourne Supremacy (2004), The Bourne Ultimatum (2007), and The Bourne Legacy (2011). These movies show a different depiction of the threat while some action movies depict the superiority of the nation in facing international threats. Rather showing the mainstream depictions of action movies, The Bourne contrastly depicts the world of action movie. It reflects a culture and collective identities steeped in marketing, popular culture, consumerism, and fear on a society (Froula, Randell, \& Birkerstein, 2010, p. 11). 
Jason Bourne as the hero of The Bourne movies is different to majority of action-spy heroes such as James Bond, Ethan Hunt, or Jack Ryan who are always depicted as being professional. Most of them work as federal agents who are specifically dealing with international issues. They, as hero, must have certain motives, such as; securing the condition and peace of the society, solving certain problems, or personal motives such as revenge (Adi, 2008, p. 68). In contrast, the hero in The Bourne Series is a man who lost his memories and only wants to know his identity. To be called as a hero, his motive is unclear as well as his mission.

The product of popular culture as a Hollywood movie that is produced by Americans reflects the beliefs and values of their society. The evolving ideas and perspectives of the society may affect the changing of the depiction inside those cultural products. Thus, the popular culture here is put on attention, because there is a mutual relationship between the society and the industry of popular culture, in which the products are reflecting the cultural values that exist in the society. There is a tendency to use popular culture to control the societies through certain depictions in it.

In this case, the tastes and values that are implied in the movies are seen from their representation through the scenes, dialogues and acts of the characters. The representation of taste may reflect the changing depiction of action in the movie. In addition, the values presented in the movies have some relation to the reception of the audiences through the popularity and profits gained by the movies. The present researcher sees The Bourne movies as the media to control the tastes and values not only American society, the global society as well. Therefore, the approach of transnational American Studies is employed in this study to identify the research problems.

\section{Methodology}

This research is conducted in the inductive qualitative methodology, as it is mainly a literature study that relies heavily on library research. Creswell explains about the qualitative research method in the book Research Design: Qualitative, Quantitative and Mixed Method Approaches, as he states that:

Qualitative research is a form of interpretive inquiry in which researchers make an interpretation of what they see, hear, and understand. Their interpretations cannot be separated from their own backgrounds, history, contexts, and prior understandings. After a research report is issued, the readers make an interpretation as well as the 
participants, offering yet other interpretations of the study (Creswell, 2003, p. 212).

In the qualitative research method, the data collection and analysis are conducted simultaneously, focusing on discovering the nature of the specific events under study through inductive reasoning. The data are presented in a straightforward manner, as a descriptive summary of the selected events resulting in a straightforward description of the phenomenon being examined.

The main purpose of this research is to seek the formation of taste and social values shaped by popular culture, especially with regard to the movie, which are not only related to the represented but also those related to the audiences' reception toward it. This research is particularly conducted to discover the formulation of these movies and the factors that made them globally popular in line with the response from audiences. The representation proposed by Stuart Hall is used to analyze the mechanism of taste and social values in the popular culture, especially in movies. This representation seeks to show what do the movies stand for, present, and represent. The data consists of images, scenes, and dialogues from each movie on The Bourne Trilogy that were selectively picked in order to understand the depiction of messages that are encoded before analyzing them using the process of decoding. These decoding and encoding processes are important to gain knowledge of American social values represented in the movies.

Furthermore, these formulations will be related to audiences' response as found in the secondary data to know whether there is a relationship between the tastes and values in the movie and the audiences or not. Since the analysis is also related to the audiences of action-spy movies, Roland Barthes' reception theory is applied. Other secondary data is utilized and taken from box office revenue to know the public reception of the movies. These secondary data will be processed and will support the finding of decoding and encoding processes. Thus, the results found from the analysis of taste and values are related to the habit of the audiences, as the concept of habitus from Herbert Gans is employed to understand whether the reaction of audiences toward the taste and social values in the movies is related to their surroundings or not. Furthermore, Foucault's concept of power is used to analyze more deeply, whether these movies tend to change or even control the society by the depictions inside it. 


\section{Discussion}

\section{Developing the Action-Spy Movie into Audiences' Desire}

Many action movies show the same depiction of the hero against the criminals who threaten and endanger the peace of the country. The introduction to the heroes and villains tends to be shown at the beginning of the narration. Moreover, those action movies illustrate the excellence of hero and his ability to pursue and capture the villain. The audience has not stopped watching action movies despite such depictions having been shown too often even by action-prone movies. This is because the audience loves the action scenes of fights between the hero and the villain shown by action movies. These action movies are also more interesting to watch because of the appearance of handsome and beautiful actors. Furthermore, the depiction of modern technological devices shown in the movies makes the acts in movies appear more convincing. Despite the formula of making no assertions about 'quality': the movies it selects for examination may or may not be the 'best' ones produced. Highlighting the function of the formula, Nachbar \& Lause (1992) stated the formula leads us to ask why these movies achieved such remarkable popularity, not to determine whether they 'deserve' to be successful (p.41).

Furthermore, there is a tendency to reproduce certain formulas of action that have already been successful in movies with the hope that the new movie will become a blockbuster. This successful formula is repeatedly demonstrated in many action movies, though the movies cast different actors and present different plots. Furthermore, the repetition of certain formulas creates a sub-genre. A movie that is considered the best by most movie critics often has many elements and is categorized by a complex combination of genres (Adi, 2008, p. 69). Some action movies tend to show the similar depiction of action from the previous movies. The example is the 007 franchise as its sequels are still produced, with the latest sequel entitled 007: Spectre released in 2015. The sequels are still about a British agent named James Bond who works for MI6. Although many actors have already played the role of James Bond, but the hero's characteristics are still the same, as he is depicted as a disobedient agent that does not follow the agency's protocols while doing his missions. The movies repeatedly depicted similar formulas of action; the luxurious sport cars, some beautiful women as supporting characters, hi-tech devices, and 
explosions. Adapting the 007 formula, the Mission: Impossible movies have also inherited the success of 007 as they are also considered as blockbuster movies.

However, Hollywood has tried to present different depiction of action genre as it combines the genre to some formulas of various genres. The first step of Hollywood in presenting different depiction of action genre was in 2002 At that time, Hollywood released the screen adaptation from Robert Ludlum's novels entitled The Bourne series, hoping the popularity of the movie will be raising as high as the novel that shows the depiction of action as the formula has flavoured with espionage. The first Bourne movie was very unexpected in the audience's eyes as if the audience's got a new experience from watching action movie. Although the profit gained by the movies was not as much as the sequel of 007 or Mission: Impossible, The Bourne series got the attention of global audiences. The first movie was released in 2002 under the title of The Bourne Identity. Doug Liman directed and the scriptwriter was Tony Gilroy for this first series. IMDb rated the movie 7.9 stars and Metacritic rated it 68\% (www.imdb.com). However, it only earned a worldwide gross of \$214.034.224 (www.boxofficemojo), which is far from competing with Mission:
Impossible II, but the movie itself was successful in capturing the audiences' attention. Responding to the audiences' curiosity about the sequel to first movie, The Bourne Supremacy was released two years later. Doug Liman was replaced by Paul Greengrass. Toni Gilroy still remained the scriptwriter for these movies. It seems that Greengrass successfully developed The Bourne movies into action movies that audiences wanted to see. Greengrass showed his capability as a professional director of action movies and this showed in the increase in profit made by the release of The Bourne Supremacy (2004). Hollywood trusted him to return to direct the third movie in the series, The Bourne Ultimatum (2007) because of the success of the second movie. Hollywood expected the third movie to be more spectacular than the previous ones and fortunately it earned $\$ 442.824 .138$ at the box office worldwide.

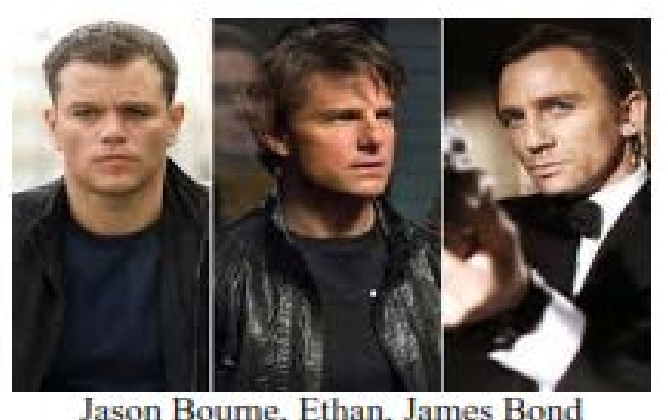

Furthermore, Hollywood released a movie that was entitled The Bourne Legacy in 2011 in order to seek more profit. This 
movie was based on book in the continued series of Ludlum's Bourne novels written by Van Lustbader, who has already written nine new novels to add to Ludlum's Bourne novel series. In the first announcement of the release date of The Bourne Legacy, many action movie lovers put high expectations on this movie because it starred by Jeremy Renner and Rachel Weisz. Another factor that is increasing the audiences' expectations toward this movie was that Tony Gilroy who was the screenwriter of the previous three The Bourne series was chosen as director of this movie. Unfortunately, the worldwide gross gained by this movie was less than the previous movies. This movie only earned $\$ 276.144 .750$ worldwide. The release of the Bourne movies can be called as an experiment of Hollywood to know the reaction and respond of audiences.

The Bourne movies challenge the established depiction of the action agent, often illustrated as someone who actively works for a certain agency such as the KGB, CIA, MI6, SWAT, or U.S. military forces. This narrative does not clearly display the hero's identity at the beginning of the movie as other action movies before did. The first movie, The Bourne Identity (2002), started by showing a man who had four bullets in his back floating in the sea was helped by a fisherman. Furthermore, the man suffers amnesia which prevents him from even remembering his name. He is only identified by a chip with a bank account implanted on his hip.

Furthermore, audiences will be confused about how to judge whether that man is the hero or not as The Bourne movies do not depict the man as a stereotypical hero that is already familiar to the audience; a handsome-man wearing a nice tuxedo who drives super modern cars and has the best weapons. The audiences get confused with the quality of the man who fits the role of hero in the action movie, as the identity of the man is not clearly presented. The identity is important for people to be able to identify each other. Margaret Wetherell (2009) explained that:

Identity draws attention to 'names' and 'looks'. It is lived out in grand narratives and performances which construct sometimes passionately invested 'imagined' routes and destinies as well as in the more mundane arenas of everyday interaction, inter-subjective relations and in social institutions. Identity guides and predicts social action. It highlights positions and intelligibility defining what is possible and livable and what is unthinkable and excessively troubled (Wetherell, 2009).

Looking to the character of the man who loses his memory in the movie, of course 
he cannot be considered as a hero. The audience is confused about whether to call the man a hero or an agent of action because the identity of that man is not clearly presented in the narration. How can the hero or agent accomplish his mission if he does not even know his identity? Using this question, the movie attracts the audiences' curiosity about discovering who the man is.



The acts inside the Bourne movies look real, as the audiences believe that they can meet those espionage activities in the real life. Although 007 and Mission: Impossible present their heroes clearly as the fights between the heroes and villains happened right after the heroes were introduced. The introduction of the hero is rarely presented by using an authorized citizenship identity card or a passport. It is different with The Bourne movies in that the hero knows his name firstly from his passports. In addition, although he has four other legal passports from four different nations with four different names, his awareness toward his identity as American makes the hero choose Jason Bourne as his name as it is printed in his United States passport.

\section{Driving Audience's Taste to Action - Spy Genre.}

Summer means not only holiday for American people but it is also a period for movie producers to release commercial movies, especially big-budget movies. The movies that are released in summer usually have the more general themes of family, action, animation, book or comic book adaptation, and sequels. The studios even schedule the release of big-budget movies in summer in order to gain the production cost back and to win box office revenue. All of The Bourne series that was produced by Universal Pictures is also released on summer. Doug Liman, the director, had approached many action actors such as Brad Pitt, Russell Crowe, Arnold Schwarzenegger, Tom Cruise and Sylvester Stallone who all refused to play the role of Jason Bourne before he cast Matt Damon. In addition, Doug Liman was not wrong in choosing Matt Damon (Hanrahan, 2007) who bravely plays dangerous scene himself while played the role of Jason Bourne. Damon even trained by a stunt choreographer, Nick Powell, for three 
months to be able to use guns and martial arts.

The proccess of casting of the main character is very important for the popularity of the movie. Audiences tend to watch a movie with famous actors or actresses in it. However, we can not say that famous actors or actresses is the important key to make a movie become popular or even be watched. In fact, some movies starred by famous actors or actresses even fail to reach popularity. The measurement of the movie's popularity is the acceptance of the audiences to the story, plot, and movie itself.

Another effort to make the movie become world wide success is screening. The movie's studios often hold private screenings for their movies, especially for small-budget movies. The studio invites movie critics, board members of the Academy of Motion Picture Arts and Sciences, and selected press to join the private screening in order to give feedback about the movie screened. The movies that are considered to be good will be nominated for the awards and be reviewed in some media. Furthermore, the media's response about whether the movie is a good or not to be watched will influence the interest of the audiences to watch it.
The important measurement of the successfull of a movie is whether it is nominated for Oscars and Golden Globe Awards or not. Winning or being merely nominated for the awards can boost not only the popularity of the movie but also the profit gained by the studio. Certain requirements must be meet for a movie to be nominated for those awards. The academy itself has strict rules about the people or movies that can be nominated. The rules are: the movie must be over 40 minutes in length; must be publicly screened for paid admission in Los Angeles County (with the name of the particular theater where it screened included); and must screen for a qualifying run of at least seven straight days (Hutchinson, 2016). In addition, the movie cannot have its premiere outside of a theatrical runscreening a movie for the first time on television or the internet.

In addition, audiences tend to watch a movie starred by famous actor or actresses. The reason is simple as they want to see their idolized actor play in the movie or even become the hero. Some audiences even do not care about the plot or the story, they are happy as long as their idols showed. However, the director can not cast some actors or actresses to his/her movies recklessly. They have to know how the 
actors or actresses casted will boost the popularity of their movies.

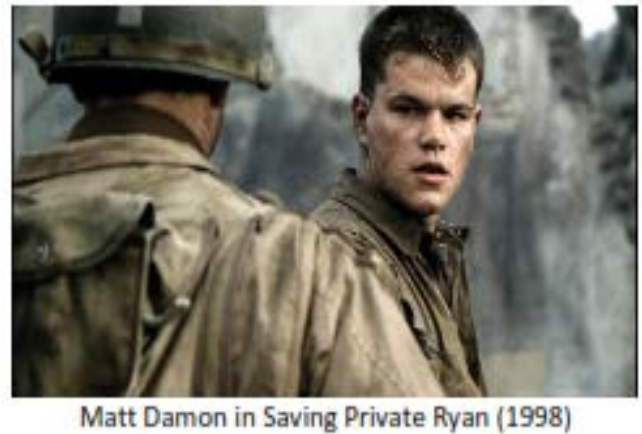

Doug Liman, the director, cast Matt Damon with several considerations. Before playing in the Bourne series, Matt Damon started his career in Mystic Pizza (1988), but the movie did not do well and his career failed to take off. Furthermore, he decided to drop out of Harvard University to focus on his career in 1993 after the release of his movie entitled Geronimo: An American Legend (1993). Damon garnered accolades for Good Will Hunting (1997), a screenplay he had originally written for an English class at Harvard University. Good Will Hunting (1997) was nominated for nine Academy Awards, one of which, Matt won for Best Original Screenplay along with Ben Affleck. In the year 1998, Matt played the title role in Steven Spielberg's movie, Saving Private Ryan (1998), which was one of the most acclaimed movies of the year. Matt Damon's most recognizable work of is his role in the Bourne movie franchise. He plays as an assassin named Jason
Bourne who suffers amnesia, in The Bourne Identity (2002), The Bourne Supremacy (2004), and The Bourne Ultimatum (2007) (www.imdb.com).

Meanwhile, the name of Doug Liman is not known by audiences as he had only directed one movie entitled See Jane Run (2001). His first movie was not categorized as a success because it did not win and was not nominated for any awards. Take a look to his records, the audiences doubted the capability of Doug Liman as the director for the next sequel of Bourne Identity (2002) as his first movie only won three awards and five nominations. Consequently, Paul Greengrasss replaced him for the Bourne Supremacy (2004) and the Bourne Ultimatum (2007). Although he did not success in the Bourne Identity (2002), Doug Liman successfully prove his capability as a director of action movie in: Mr.\&Mrs. Smith (2007) and Edge of Tomorrow (2014) which are box office hits. Meanwhile, Paul Greengrass brought the Bourne movies success as the Bourne Supremacy (2004) won 5 awards and 21 nominations (www.imdb.com). Fortunately, the Bourne Ultimatum (2007) inherited the success of its predecessor as it won 3 Oscars, another 25 wins, and 38 nominations (www.imdb.com). 
There is a tendency that the studio will make more of an effort to make the sequels more successful than the pilot movie. One way that this is accomplished is by the studio replacing the movie director, especially for a movie series that cannot live up to the expectation of the studio. By replacing the director, the hope is that the movie will become more popular. Another way is by increasing the budget for the next sequels if they think the sequels are more promising than the pilot movie. The first Bourne movie, The Bourne Identity (2002), that was released to compete with other summer blockbusters on June 14, 2012 only received a budget of $\$ 60.000 .000$. Doug Liman as the movie director was unsuccessful as the movie only grossed \$121,661,683 by November 21, 2002. Dissatisfied by the achievement of this movie, the studio took several steps for the next movies. Expected to be more popular than the Bourne Identity, the studio increased the budget up to $\$ 75.000 .000$ as they trusted Paul Greengrass to be the director of the second movie, the Bourne Supremacy. He was successful in making audiences love the movie that turned into a super-fast paced action movie as the movie earned \$176.049.130. Furthermore, the studio increased the budget for the third movie, The Bourne Ultimatum (2007), higher than the budget for the second movie. The third movie that won three Oscars was budgeted at $\$ 110.000 .000$.

The audiences are slowly driven to accept and watch a brand new depiction of action that is mixed by espionage in Bourne movies by the movie makers. Several ways that had been conducted by movie makers are (1) Casting the promised actor as Matt Damon to attract the interest of audiences. (2) Changing the director from Doug Liman to Paul Greengrass in order to make the movie become more popular. (3) Increasing the production budget for the continuation sequel. (4) Hold a movie screening project to get positive review from movie reviewer. (5) Participating in some nomination awards as Oscar in order to win the nomination and popularly known. These ways are really effective in driving the audience's taste from pure action genre movies to action-spy genre movies. The success of the movie makers in making the audience loves Bourne movies can be seen as the instalment of the fourth movie of Bourne.

Many audiences hope that they will see the heroic action of Matt Damon in the fourth movie entitled Bourne Legacy. After the success of the previous three Bourne movies that were adapted from Robert Ludlum novels, the studio made the third 
installment based on the continuation of the Bourne novel written by Van Lustbader under the title The Bourne Legacy. The Bourne movielovers expected to see Jason Bourne in the fourth movie as the title still used the name Bourne. However, the movie dissatisfied audiences' expectations. The movie did not star Matt Damon rather it starred Jeremy Renner and Rachel Weisz. Instead of having Jeremy Renner step into the role of Jason Bourne, the moviemakers created another character in the same nature as Jason Bourne. "The problem is, viewers are invested in Bourne and not seeing him in the movie that bears his name feels like a cheat (Berardinelli, 2012)." Although this movie was budgeted around \$125.000.000 which is higher than the previous three Bourne movies, its gross was less than the first Bourne movie. Consequently, the movie won only 1 award and 11 nominations.

\section{The Emergence of American Values in the Heroes Existence}

People have their own standards of what the hero of action movies should be. Many of them think that the hero must be perfect, have more abilities than the enemies, loved by many people around, and etc. However, the fact that make people idolize a hero is because there are similarity in the social values between them and the characters of the hero.

People often think that the hero in an action movie will not be different to other hero in the previous action movies. In example, the name Jason Bourne which sounds a lot like James Bond made audiences put higher expectations on the Bourne movies as action movies. Furthermore, the popularity of the novel made audiences expect something as exciting as was depicted in the novel. The differences in the characterization and the depiction of action in The Bourne movies compared to other action movies became the uniqueness of these movies. The Bourne series showed the depiction of American espionage and American heroes while other action movies still adapted British classical detective fiction with glamorous heroes.

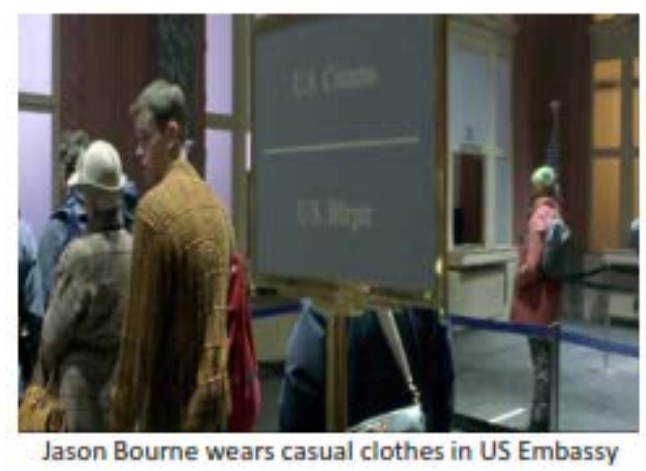

The leading character of the movie called hero is the main subject that leads the narrative, so there is a certain emphasis in the characterization. The hero or heroine 
in the movie is given certain power so that they are able to solve and conclude the narrative. The hero has to be an expert who is aware of his role and identity as a hero and works for a certain agency under government supervision: 007, Mission: Impossible, the Jack Ryan series, and Kingsman Secret Service (2015). Because of this, the hero of action-spy movie is generally assumed to be an agent of government. However, the characteristics of Jason Bourne as an action-spy hero seemingly counters the stereotypes of the hero in action-spy movies that mostly occurs as British agent. Jason Bourne celebrates the American identity and social values of innocence and self-reliance. Countering this general characterization of a spy, Jason Bourne first appears as the most wanted fugitive of the CIA and he is not aware of his identity as he lost his memory.

Jason Bourne who represents the identity and values of Americans does not wear elegant suits like Bond and Hunt. He wears casual shirts like a typical American. He is very independent as he does not seek any help while searching for his identity and revealing the corruption of CIA. The social value of individuality of American is embodied in the figure of Jason Bourne. Heroes reflect the highest goals of culture embodied in the life and the image of a specific individual (Nacbar \& Lause, 1992, p. 26). Here, Jason Bourne is an embodiment of American individuality. The Bourne series does not criticize the value of American society through the narrative rather it celebrates American values.

In order to gain popularity and high box office revenue, the movie has to attract large audiences. Thus, a certain requirement that is universally accepted by American society has to be fulfilled, which includes social values and norms. To please the audiences, "the producers of popular culture (movie) will go to great lengths to mold their products to reflect the audience beliefs and values” (Nachbar\&Lause, 1992, p. 3). In this case, although Jason Bourne is a spy, the moviemakers decided to depict him as an ordinary American as reflected in his appearances.

Nachbar \& Lause (1976) argued that the traditional American beliefs and values in the box office top ten are individual freedom, technology as protector and savior, violence as a legitimate means of obtaining justice outside the law, youth as the best period of life and childhood in particular as a special time which needs to be protected and preserved (p. 47-50). Thus, The Bourne movies carry the belief 
of individual freedom as Jason Bourne wants to live his own life without any assassins hunting him and they carry the idea that the CIA uses violence as a legitimate means of obtaining justice outside the law. Jason Bourne struggles for his freedom as well as his desire to know his identity.

The Bourne movies present the idea of individualism as it reflects on the hero's efforts to gain his identity and to fix misunderstanding that put him as a criminal. Jason Bourne, the hero, relies on himself without any help from other people. $\mathrm{He}$ is an embodiment of individualism as "heroes reflect the highest goals of culture embodied in the life and the image of a specific individual (Nachbar\&Lause, 1992).” Although he has a girlfriend, he does everything himself. He feels that fixing the misunderstanding that caused him to be blamed for the CIA corruption is his obligation. He has to force himself to be able to survive the assassination attempts directed at him by bad CIA officers.

The depiction of individualism as shown in The Bourne movies is different compared to other action movies. For example, James Bond does not reflect the individualism of America as he is always assisted by the MI6 organization. He always runs to the organization to obtain some help in fixing his car or rearming himself with guns and other modern weapons. Similar to Bond, Ethan Hunt in Mission: Impossible is supported by his IMF team. However, Jason Bourne relies on himself to face all his enemies with anything he finds. He hijacks cars and motor cycles, uses weapons taken from enemies that he defeated and treats his own wounds. Jason knows that technology has a good and bad side that depends on the user. As he knows that the CIA has strong surveillance capabilities, Bourne prefers to keep himself away from cell phones, security cameras, and internet.

In the end, as explanation, there are two fundamental beliefs marking the characteristics of American society. Coming from their ancestors' ideas that society was composed of free and equal individuals, as they should preserve the value of individualism. According to Ralph Waldo Emerson, the idea of individualism born to encourage Americans to distinguish themselves from Britain and Europe. The idea of individualism is actually "to believe your own thought, to believe that what is true for you in your private heart that is true for all men, - that is genius. Speak your latent conviction and it shall be the universal sense: for the inmost in due time 
becomes outmost (Emerson, 2001).” Individualism is a myth - whether it is a story or real legend in American history. "Myths are stories, drawn from history that have been acquired through cultural functioning of the society that produced them, historical experience is preserved in the form of narrative, and through periodic retellings those narratives become traditionalized (Slotkins, 1985).” In reality, this individualism is embodied in American society whether realized or not. The believer of this self-reliance and individualism is increasing as one realizes that he/she cannot depend on others help except himself/herself to life. That is why Frye (1990) argues, "A myth to me is primarily a mythos, a story, narrative, or plot, with a specific social function (p. 28)." Myth works in the society as it influences people's behavior. Moreover, the members of a society who lives inside the same myth will share the same perception of it. Thus, the moviemakers make the American value embodies in the representation of a hero as Jason Bourne in action movies, which is not to counter or to deny the existence of those values rather to celebrate and to let the world know about it.

\section{Conclusion}

The Bourne movies present different depictions of action in the American cinema. First, the movies have so many elements of fiction that some people categorize its genre as action-spy movies while the other people consider them action-thrillers. Movies that are categorized into more than one genre will be more fascinating for the audiences. Second, the characterization inside the movies is different from the action movies that preceded it. The introduction of characters in the series is not directly presented in the beginning of the movie but rather it is revealed by the situation. The way of this characterization is not common for movies in the action genre, since it occurs commonly in the movies under suspensethriller genre. Third, the emergence of a hero in The Bourne movies is not presented with a clear introduction as in the majority of box office action movies. The amnesia suffered by the hero character is the key to attracting the curiosity of the audience as they want to know the identity of the hero. Fourth, Jason Bourne and Aaron Cross are different from other heroes in action movies because they are not working for a certain organization under the supervision of a government. They are not depicted as fashionable heroes who wear nice suits and 
drive nice cars. Instead, they wear casual outfits; shirts, jackets, and jeans as a typical American. In conclusion, popular Hollywood movies follow traditional movie formats in their portrayal of heroes and villains with an American hero, most often a white Anglo- Saxon male.

The main factor that reformulated the depiction of action and the formula in Hollywood movies is the changing of the audiences' tastes and reception to the values shown in the movies. A movie is a reflection of the society as well as the beliefs, tastes, values, and ideas of myths that may change into something different over time. That is why the tastes and values that exist in the society where the audiences come from must be presented in it. Regarding the audiences' background, taste is very subjective as well as influenced by the imaginary built inside each audience. However, Hollywood controls the society's reception through the adjustment of taste and the dramatization of American values portrayed in its action movies especially Bourne movies. To attract mass audience, a movie has to satisfy the desires of its audiences. Since audiences’ tastes are vary, some fiction formulas are mixed to create certain depictions in the movie. The social values implied are used to make the audiences accepted the depiction in the movie. The social values are usually presented through the existence of the heroes as it is embodied in the heroes' appearance. In the Bourne movies, Jason Bourne and Aaron Cross as the heroes in the movies reflect the individualism, freedom, and innocence of American values through their actions. They present individualism through the actions they take to solve problems. Both of them want only their freedom to live without any assasination attempt directed to them. In addition, the movies and movie industry do not criticize a certain social values of society but rather dramatizes them to make their movies are accepted by worldwide audiences.

\section{References}

Adi, I. R. (2011). Fiksi Populer: Teori \& Metode Kajian. Yogyakarta: Pustaka Pelajar.

Adi, I. R. (2008). Mitos dibalik Movie Laga Amerika. Yogyakarta: Gadjah Mada University Press.

Cawelti, J. G. (1976). Adventure, Mystery, and Romance: Formula Stories as Art and Popular Culture. Chicago: University of Chicago Press.

Creswell, J. W. (2003). Research Design, Second Edition. Thousand Oaks,: Sage Publication.

Froula, A., Randell, K., \& Birkerstein, J. (2010). Reframing 911: Movie, Popular Culture, and the "War on 
Terror". New York: The Continuum International Publishing Group Inc.

BIBLIOGRAPHY Gilroy, T. (Director). (2012). The Bourne Legacy [Motion Picture]. Universal International Picture, Intermovie Cinema, Solar Entertainment.

Greengrass, P. (Director). (2004). The Bourne Supremacy [Motion Picture]. USA / Germany: Universal Studio, Universal Pictures, Buena Vista International.

Greengrass, P. (Director). (2007). The

Bourne Ultimatum [Motion Picture].

Hall, S. (2005). Culture, Media, Language. New York: Taylor \& Francis eLibrary.

Hutchinson, S. (2016, January 20). How Are Oscars Nominees Choosen? Retrieved June 14, 2016, from Mental_floss:

http://mentalfloss.com/article/54560 /how-are-oscar-nominees-chosen

IMDb. (n.d.). Matt Damon Bibliography. Retrieved June 14, 2016, from IMDb:

http://www.imdb.com/name/nm000 0354/bio?ref_=nm_ov_bio_sm

Internet Movie Database. (2015). Tom Cruise - Biography - iMDB. Retrieved from Internet Movie Database:

http://www.imdb.com/name/nm000 0129/bio?ref_=nm_ov_bio_sm\#sala ry

Jenkins, T. (2012). The CIA in Hollywood: How The Agency Shapes The Movie and Television. United States: University of Texas Press.
Liman, D. (Director). (2002). The Bourne Identity [Motion Picture]. USA, Germany, Cezch Republic: Universal Picture, East West, United International Picture.

Nachbar, J., \& Lause, K. (1992). Popular Culture: An Introductory Text. USA: Bowling Green University Popular Press.

Paine, T. (1945). Common Sense. (P. S. Foner, Ed.) New York: The Citadel Press.

Tudor, A. (1986). Genre. In B. K. Grant, Movie Genre Reader (p. 8). Austin, Texas: University of Texas Press.

Yeung, A. (2015, August 11). 2015's Most Successful Movie Marketing Campaigns: Summer Blockbuster Edition. Retrieved June 13, 2016, from mavrck: http://www.mavrck.co/2015s-mostsuccessful-movie-marketingcampaigns-summer-blockbusteredition/

\section{SUBJECT INDEX:}

Action-Spy

American

American values

Audience

Bourne

Culture

Espionsge

Movie

Formula

Freedom
Hero

Hollywood

Individualism

Knowledge

Popular

Power

Representation

Reseption

Self-reliance

Taste 